Jin-Bo Guo* and Guan-Feng Li

\title{
Crystal structure of poly[dibromido-bis $\left(\mu_{2}-1,6-d i\right.$ (1H-imidazol-1-yl)hexane- $\left.{ }^{2} N: N^{\prime}\right)$ cadmium(II)], $\mathrm{C}_{24} \mathrm{H}_{36} \mathrm{Br}_{2} \mathrm{~N}_{8} \mathrm{Cd}$
}

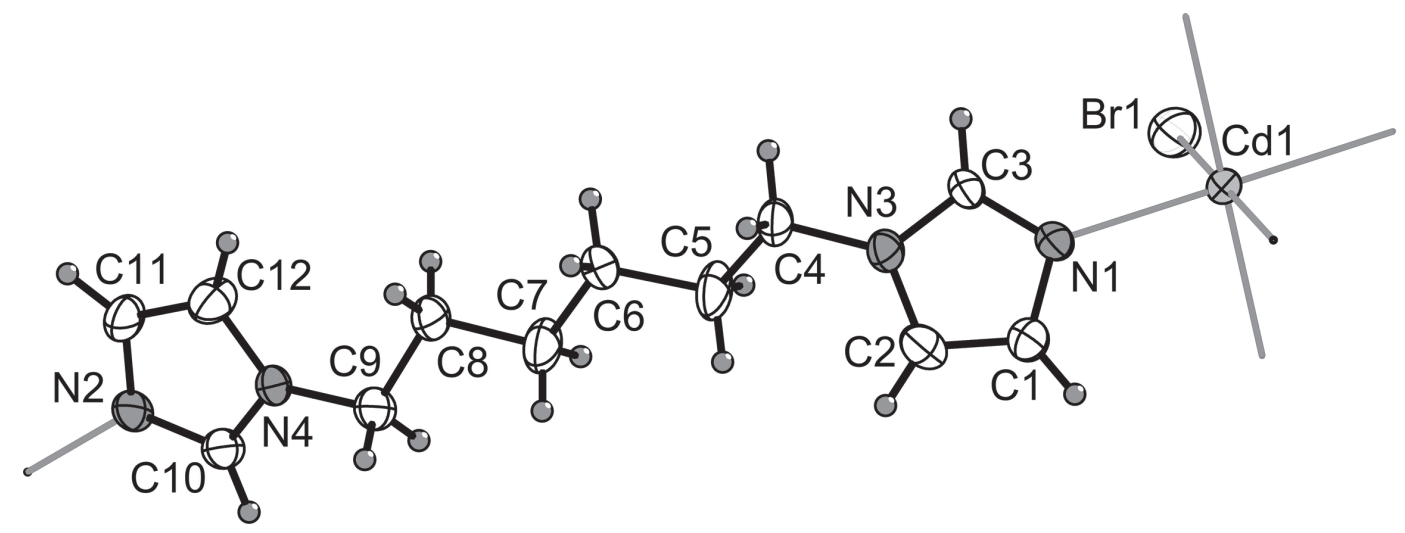

https://doi.org/10.1515/ncrs-2020-0217

Received May 4, 2020; accepted June 10, 2020; available online June 20,2020

\section{Abstract}

$\mathrm{C}_{24} \mathrm{H}_{36} \mathrm{Br}_{2} \mathrm{~N}_{8} \mathrm{Cd}$, monoclinic, $P 2_{1} / c$ (no. 14), $a=9.6915(4) \AA$, $b=7.6614(2) \AA, \quad c=19.0851(8) \AA, \quad \beta=100.529(4)^{\circ}$, $V=1393.21(9) \AA^{3}, Z=2, R_{\mathrm{gt}}(F)=0.0744, w R_{\mathrm{ref}}\left(F^{2}\right)=0.1823$, $T=293(2) \mathrm{K}$.

\section{CCDC no.: 2009038}

The asymmetric unit of the polymeric title structure is shown in the figure. Table 1 contains crystallographic data and Table 2 contains the list of the atoms including atomic coordinates and displacement parameters.

\section{Source of material}

A mixture of $\mathrm{Cd}\left(\mathrm{NO}_{3}\right)_{2} \cdot 2 \mathrm{H}_{2} \mathrm{O}(0.1 \mathrm{mmol}, 0.0272 \mathrm{~g}), 1,6-\mathrm{di}$ (1H-imidazol-1-yl)hexane (1,6-dih) (0.2 mmol, $0.0612 \mathrm{~g}), \mathrm{HBr}$ $(0.1 \mathrm{mmol} / \mathrm{mL}, 2 \mathrm{~mL})$, was dissolved in $9 \mathrm{~mL} \mathrm{H}_{2} \mathrm{O}$. Then the solution was heated in a $23 \mathrm{~mL}$ Teflon-lined autoclave under autogenous pressure at $373 \mathrm{~K}$ for 4 days. After cooling to room

*Corresponding author: Jin-Bo Guo, College of Chemistry and Chemical Engineering, Luoyang Normal University, Luoyang, Henan 471934, P.R. China, e-mail: guojb2020@126.com. https://orcid.org/ 0000-0001-5050-5531

Guan-Feng Li: College of Chemistry and Chemical Engineering, Luoyang Normal University, Luoyang, Henan 471934, P.R. China

ð Open Access. ( 2020 Jin-Bo Guo et al., published by De Gruyter. (c) BY International License.
Table 1: Data collection and handling.

\begin{tabular}{ll}
\hline Crystal: & Colourless block \\
Size: & $0.42 \times 0.38 \times 0.26 \mathrm{~mm}$ \\
Wavelength: & Mo $K \alpha$ radiation $(0.71073 \AA)$ \\
$\mu:$ & $3.68 \mathrm{~mm}^{-1}$ \\
Diffractometer, scan mode: & EosS2, $\omega$ \\
$\theta_{\text {max }}$, completeness: & $25.5^{\circ},>99 \%$ \\
$N(h k l)_{\text {measured }}, N(h k l)_{\text {unique }}, R_{\text {int }}:$ & $29900,2585,0.084$ \\
Criterion for $I_{\text {obs }}, N(h k l)_{\text {gt }}:$ & $I_{\text {obs }}>2 \sigma\left(I_{\text {obs }}\right), 2356$ \\
$N(\text { param })_{\text {refined }}:$ & 160 \\
Programs: & CrysAlis \\
\hline
\end{tabular}

temperature crystals formed. The colourless crystals suitable for X-ray diffraction analysis were collected.

\section{Experimental details}

Coordinates of hydrogen atoms were included using riding models (AFIX 23 and AFIX 43 [3]). Their $U_{\text {iso }}$ values were set to $1.2 U_{\text {eq }}$ of the parent atoms.

\section{Comment}

The design and construction of metal-organic frameworks (MOFs) is the hottest research in the last decade. The organic ligands, which have their differences in the size, the exibility, the coordination ability, the number of the $\mathrm{N}$-donor ligands, such as 1,6-bis(1,2,4-triazol-1-yl)hexane, have significant influence on structure of final product [4]. The flexibility of $\mathrm{N}$-donor ligands can result not only in gauche and anti conformations in coordination, but also in free rotation to 
Table 2: Fractional atomic coordinates and isotropic or equivalent isotropic displacement parameters $\left(\AA^{2}\right)$.

\begin{tabular}{lrrrr}
\hline Atom & $\boldsymbol{x}$ & $\boldsymbol{y}$ & $\boldsymbol{z}$ & $\boldsymbol{U}_{\text {iso }}{ }^{*} \boldsymbol{U}_{\text {eq }}$ \\
\hline Cd1 & 1.0000 & 1.0000 & 0.5000 & $0.0342(3)$ \\
N1 & $0.9210(7)$ & $0.8669(9)$ & $0.3905(3)$ & $0.0282(15)$ \\
N2 & $0.2051(7)$ & $-0.3326(9)$ & $0.0207(4)$ & $0.0305(16)$ \\
N3 & $0.8798(7)$ & $0.6851(9)$ & $0.3003(4)$ & $0.0287(15)$ \\
N4 & $0.3487(7)$ & $-0.1193(9)$ & $0.0619(4)$ & $0.0280(15)$ \\
Br1 & $0.86144(11)$ & $0.73774(13)$ & $0.57319(6)$ & $0.0473(3)$ \\
C1 & $0.8350(10)$ & $0.9451(12)$ & $0.3351(5)$ & $0.036(2)$ \\
H1 & 0.7997 & 1.0578 & 0.3356 & $0.043^{*}$ \\
C2 & $0.8086(9)$ & $0.8336(12)$ & $0.2787(5)$ & $0.036(2)$ \\
H2 & 0.7531 & 0.8550 & 0.2343 & $0.044^{*}$ \\
C3 & $0.9464(9)$ & $0.7094(11)$ & $0.3678(4)$ & $0.0285(18)$ \\
H3 & 1.0028 & 0.6265 & 0.3948 & $0.034^{*}$ \\
C4 & $0.8764(9)$ & $0.5245(12)$ & $0.2582(5)$ & $0.037(2)$ \\
H4A & 0.9293 & 0.4343 & 0.2870 & $0.044^{*}$ \\
H4B & 0.9208 & 0.5458 & 0.2174 & $0.044^{*}$ \\
C5 & $0.7289(10)$ & $0.4622(13)$ & $0.2328(6)$ & $0.046(3)$ \\
H5A & 0.6770 & 0.5541 & 0.2045 & $0.055^{*}$ \\
H5B & 0.6853 & 0.4434 & 0.2740 & $0.055^{*}$ \\
C6 & $0.7149(9)$ & $0.2971(12)$ & $0.1890(5)$ & $0.036(2)$ \\
H6A & 0.7665 & 0.3102 & 0.1503 & $0.043^{*}$ \\
H6B & 0.7563 & 0.2009 & 0.2186 & $0.043^{*}$ \\
C7 & $0.5651(10)$ & $0.2547(13)$ & $0.1588(6)$ & $0.047(3)$ \\
H7A & 0.5298 & 0.3412 & 0.1229 & $0.057^{*}$ \\
H7B & 0.5109 & 0.2652 & 0.1966 & $0.057^{*}$ \\
C8 & $0.5391(9)$ & $0.0740(12)$ & $0.1255(5)$ & $0.037(2)$ \\
H8A & 0.6051 & 0.0531 & 0.0938 & $0.044^{*}$ \\
H8B & 0.5546 & -0.0139 & 0.1626 & $0.044^{*}$ \\
C9 & $0.3931(9)$ & $0.0587(11)$ & $0.0847(5)$ & $0.035(2)$ \\
H9A & 0.3292 & 0.1038 & 0.1140 & $0.041^{*}$ \\
H9B & 0.3844 & 0.1322 & 0.0427 & $0.041^{*}$ \\
C10 & $0.2153(9)$ & $-0.1685(11)$ & $0.0406(5)$ & $0.0307(18)$ \\
H10 & 0.1387 & -0.0951 & 0.0400 & $0.037^{*}$ \\
H11 & $0.3402(10)$ & $-0.3922(12)$ & $0.0294(5)$ & $0.039(2)$ \\
H12 & 0.3665 & -0.5045 & 0.0189 & $0.047^{*}$ \\
H4 & $0.4306(9)$ & $-0.2609(12)$ & $0.0561(5)$ & $0.039(2)$ \\
H & 0.5279 & -0.2672 & 0.0679 & $0.047^{*}$ \\
\hline
\end{tabular}

meet the requirements of the coordination geometry of the metal ions in the assembly process. The organic ligand 1,6di(1H-imidazol-1-yl)hexane serves as bridging ligand [5-8].
In the title complex, there are one half of a $\mathrm{Cd}(\mathrm{II})$, one (1,6-dih) ligand, and one bromide in the asymmetric unit. The cadmium atom $\mathrm{Cd} 1$ is six-coordinated with a distorted octahedral geometry by four $\mathrm{N}$ atoms from the 1,6-dih ligands from the axial positions (see the figure). The $\mathrm{Cd}-\mathrm{Br}$ bond length is 2.9121(11) $\AA$; and the $\mathrm{Cd}-\mathrm{N}$ ones are in the range of 2.325(6) to 2.338(7) $\AA$, respectively. The bond angles of $\mathrm{N}-\mathrm{Cd}-\mathrm{N}$ are in the range of $87.6(2)^{\circ}$ to $180^{\circ}$.

Acknowledgements: The authors thank the Key Scientific Research Project for Universities of Henan Province (No. 18B150015; No. 20A150028) and Science and Technology Research Project of Henan Province (no. 182102310909) for financial support.

\section{References}

1. Agilent Technologies: CrysAlis ${ }^{\text {PRO }}$ Software system, version 1.171.35.15. Agilent Technologies UK Ltd, Oxford, UK (2011).

2. Sheldrick, G. M.: SHELXT - Integrated space-group and crystal-structure determination. Acta Crystallogr. A71 (2015) 3-8.

3. Sheldrick, G. M.: Crystal structure refinement with SHELXL. Acta Crystallogr. C71 (2015) 3-8.

4. Li, S. H.; Wu, H. X.; Chai, N.: A cobalt(II) complex based on 5methoxyisophthalic acid and 1,6-bis(1,2,4-triazol-1-yl)hexane: synthesis, crystal structure and magnetic properties. Synth. React. Inorg. Met.-Org. Nano-Met. Chem. 43 (2013) 1487-1491.

5. Song, W.; Li, S. H.; Xu, X. L.: Crystal structure of catenapoly[triaqua-(isophthalato- $\mathrm{k} O)$ - $\left(\mu_{2}-1,6\right.$-di $(1 \mathrm{H}$-imidazol-1-yl) hexane- $\left.\left.{ }^{2} N: N^{\prime}\right)\right]$ nickel(II). Z. Kristallogr. NCS 233 (2018) 173-175.

6. Zhao, Y.; Wang, K. Q.: Crystal structure of poly[2-1,4-di(1Himidazol-1-yl)butan- $\mathrm{K}^{2} \mathrm{~N}: \mathrm{N}^{\prime}$-2- thiophene-2,3-dicarboxylato$\mathrm{K}^{4} O, O^{\prime}: O^{\prime \prime}, O^{\prime \prime \prime}$ nickel(II)]. Z. Kristallogr. NCS 228 (2013) 363-364

7. Li, S. H.; Li, X. L.: A cadmium complex based on 5 methylisophthalic acid and 1,6-bis(imidazol-1-yl)hexane: synthesis, crystal structure, and photoluminescence properties. Synth. React. Inorg. Met.-Org. Nano-Met. Chem. 43 (2013) 710-713.

8. Bao, W.-L.: catena-poly[[dichloridozinc(II)]- $\mu-1,1^{\prime}$-(hexane-1, 6-di-yl)di-imidazole- ${ }^{2} N^{3}: N^{3}$ ]. Acta Crystallogr. E65 (2009) m1239. 